\title{
You Are Not Logged In: Context and Interpersonal Meaning of Instructions and Links in a typical Learning Management System
}

\author{
Hakeem Olafemi Ogunmuyiwa \\ English Language Institute (ELI), Jubail Technical Institute, Royal Commission for Jubail \\ Jubail Industrial City, Kingdom of Saudi Arabia \\ E-mail: Ogunmuyiwa_h@jti.edu.sa
}

Received: 19-08-2016

Published: 10-12-2016
Accepted: 28-10-2016

doi:10.7575/aiac.ijalel.v.5n.7p.241
Advance Access Published: November 2016

URL: http://dx.doi.org/10.7575/aiac.ijalel.v.5n.7p.241

\begin{abstract}
It is common knowledge that the incorporation of Learning Management Systems (LMS) in ESL/EFL instruction has enhanced learners understanding of the language just as it has helped teachers in monitoring students' progress. However, the use of these eLearning platforms can be quite challenging for EFL learners who are yet to be proficient in the English language. This is because all course information and instructions are offered in the language. Following the notion of context and language metafunctions by Halliday (1985) and his followers, analysis of some linguistic expressions in typical learning management systems is conducted. I show how context and interpersonal meanings are established, and how they can enhance learners' comprehension of information and instructions. The linguistic expressions used as data are sourced from student-specific pages of the web-based Learning Management System (Blackboard) and the Modular Object-Oriented Dynamic Learning Environment (Moodle) as adapted in colleges and institutes in Saudi Arabia.
\end{abstract}

Keywords: Systemic Functional Linguistics, Interpersonal Meaning, Mood, Context, Learning Management Systems

\section{Introduction}

The use of online course management systems (CMS) otherwise referred to as virtual learning environment (VLE) or learning management system (LMS) in ESL/EFL teaching is undoubtedly gaining more awareness day-by-day as educational institutions strive to provide learners with learning opportunities that complement face-to-face classroom interaction and teaching endeavors. This is not unconnected to its multiple benefits. Murray and Mcpherson (2004, p.65) explain that LMS helps students participate in a course from a distance or at their convenience; collaborate and negotiate in English with peers to meet objectives and review course content in their own time. For teachers, it helps them reflect on both the 'product and process of learning' (see also, Johnson 2003). This is as a result of the fact that interactions with students via this medium can be captured, kept and archived. They also help teachers integrate the web as an information source with materials produced by teachers, and with interactive online communication as may be done through answering questions, feedbacks, blogs and emails. For teachers and students alike, King Koi (2002) maintains that it provides an opportunity for individualized instruction capable of meeting the needs of disparate learners in the same class.

A number of learning systems have been developed. For the purpose of this paper, I refer to them as learning management systems (henceforth LMS). Some of them are proprietary while others are open source. Central to effective maximization of LMS is language. What learners are expected to do in terms of activities and how they are to do it are all expressed using the instrument of language. It is therefore imperative for learners to understand the ramifications of meaning of any linguistic structures found in their adopted LMS. The functional approach to language provides interesting perspectives by which appropriate understanding can be achieved. This is the gap that the functional approach to language learning comes to fill.

It is, thus, clear that language does more than showing and enacting our experience. The use of language can express the kind of relationship that exists between interactants, be it in speech or writing. Within the functional perspective to language study, the aspect that expresses the kind of roles and relationships that may exist in language communication is called interpersonal metafuntion. Interpersonal metafunction is part of the three metafunctions advanced by MAK Halliday, the 'father' of Systemic Functional Linguistics (SFL). The other two are experiential (ideational) and textual metafunctions.

Halliday views language as not just as a system of rules which govern language structure, but rather, one with meaning potential (Halliday, 1973:346). This is a departure from the perspective of traditional language studies, including traditional school grammar, where there is no commitment to the study of meaning in language. Halliday believes that the process of acquisition and understanding is inclusive of "mastering certain basic functions of language and developing a meaning potential for each" (1975:33). In traditional school grammar, the categories or classes of words 
found in English such as nouns, verbs, adverbs and the like are most prominent. Although some of these word class labels are retained in SFL, but the theory also uses many other functionally relevant terms like participants (nominal), processes (verbs), circumstances (adverbials etc.), theme or rheme which are essential because "they are part of the general enterprise of exploring how people construct and negotiate meanings in the many contexts in which they interact" (Christie and Unsworth, 2000). From the dimension of language learning, Halliday (1973) canvasses for the need to see language acquisition as the mastery of linguistic functions. He argues that "learning one's mother tongue is learning the uses of language, and the meanings, or rather the meaning potential, associated with them. The structures, the words and the sounds are the realization of this meaning potential. Thus the process of language learning is learning how to mean (Halliday 1973, p345; see also Saville-Troike, 2006).

Coming from the perspective of language learning, Saville-Troike (2006) distinguishes the functional approach from the Chomskyan tradition. Accordingly, there is no sharp distinction between the use of language in real situations (performance) as well as underlying knowledge (competence). Also, the study of second language from the functional perspective begins with the assumption that the purpose of language is communication, and that development of linguistic knowledge (be it in First or Second Language) requires communicative use. Finally, the scope of concern goes beyond the sentence to include discourse structure and how language is used in interaction, and to include aspects of communication beyond language (see also, Tomlin 1990). Tomlin $(1990, \mathrm{p} 155)$ admits that the functional approach "represents a comprehensive orientation to matters of language use and interaction which underlie and affect the temporal acquisition of second languages".

The current study may, therefore, be justified in the sense that various learner information, links and instructions in LMS are structurally constructed different forms ranging from a single lexical item to (short) phrases or groups and clauses/sentences. Learners (regardless of their English language proficiency level) are expected to create meaning and understand instructions in order to do the required studies, assignments, tests and other interaction endeavors. Learners' understanding of what is required in terms of instruction may be enhance by an understanding of the context. Thus, an understanding of certain linguistic strategies may greatly help.

\section{Previous studies, problems, aim and objectives}

Investigations have been carried on the learners' challenges in using the online course management systems. Al-Jarf (2005, p.7) has examined whether the complexity of an online course design can affect its frequency of usage. He also identifies technological and linguistic barriers to students' participation and interaction. In doing a juxtaposition of three online management course systems (Nicenet, WebCT and Moodle), he points out that linguistic factors relating to learners limited proficiency affect understanding; adding that 'Moodle and WebCT use many technical terms with which the students were not familiar'.

Berg and Lu (2014, p. 326-328) also conducted a research on Student Attitudes towards Using Moodle as a Course Management System. Using the Taiwanese context, the research was conducted using the population 86 students studying English in a Department of Applied Foreign Languages undergraduate degree program at a private university in central Taiwan. According to them, the analyzed data show that 'students are not overly satisfied with using Moodle, but they do agree that it offers great functionality for learning outside the classroom' (Berg and Lu, 2014). One of the reasons which may be adduced to this seemingly dissatisfaction is problem relating to language. As alluded by Al-Jarf (2005), technical expressions or expressions with multiple semantic implications may be too complex for adequate understanding for learners with limited proficiency.

With linguistics theory such as Systemic Functional Linguistics (henceforth SFL), understanding concepts in functionalism such as the context of situation (COS) and language metafunctions are some of the resources in understanding of the language of LMS is built on. Developed in the early 1950s, SFL is a model for analyzing language in terms of the interrelated systems of choices that are available for expressing meaning. Basic to the approach is the notion, which is also derived from the anthropologist Bronislaw Malinowski, that language structures cannot be idealized and studied without taking into account the circumstances of their use, including the extralinguistic social context (Saville-Troike, 2006, Halliday, 1991).

Halliday and Hassan $(1985,1989)$ examine context from two major perspectives namely; context of situation (COS) and context of culture (COC). Our focus is on context of situation as it makes reference to the environment, time and place of discourse. From Hallidayan perspective, context of situation is 'the immediate environment in which a text is actually functioning'. 


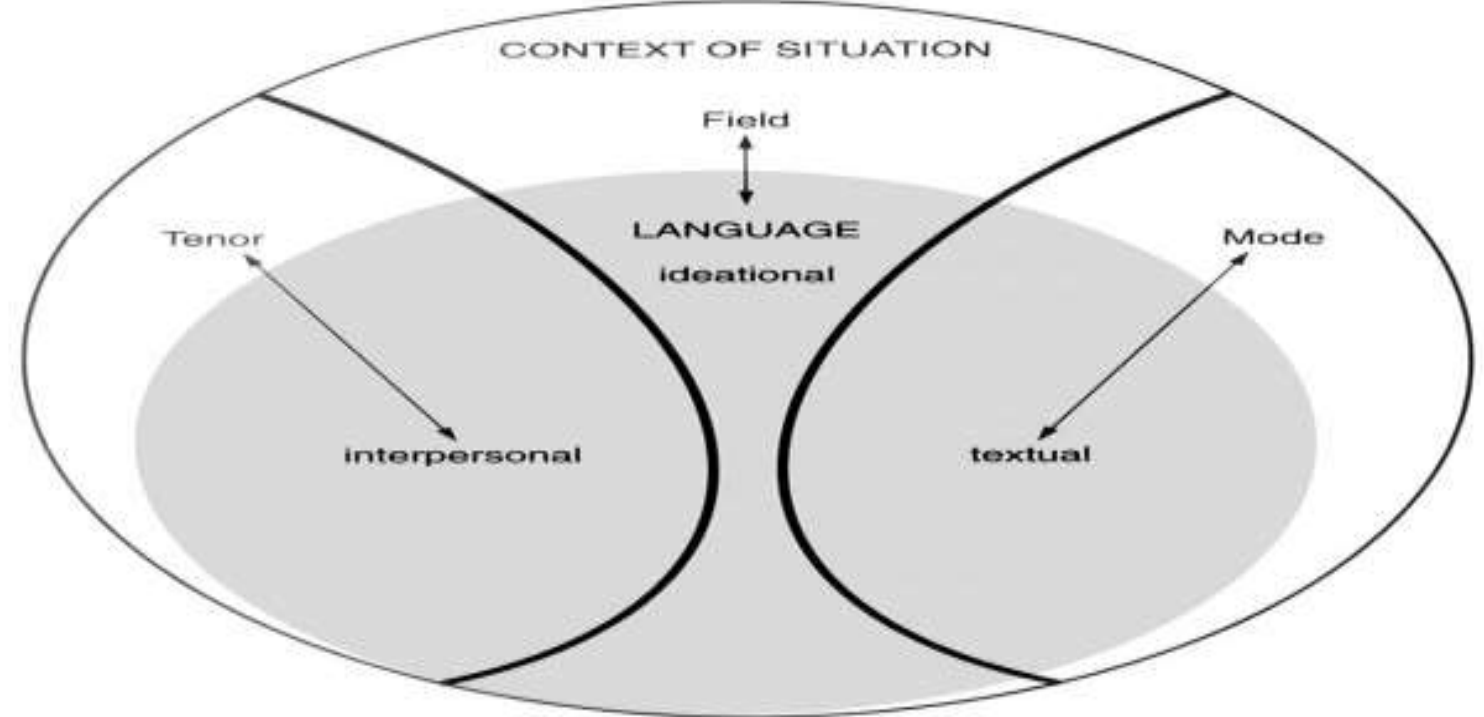

Figure 1. The figure explains the context of situation (adapted from Frances Christie and Len Unsworth, 2000)

They approach the study of context from what they called field, tenor, and mode. Halliday and Hassan (1985, p. 29-30) maintain that the field of discourse refers to 'the kind of activity, as recognised in the culture, within which language is playing some parts'. The tenor of discourse refers to 'the actors, or rather the interacting roles that are involved in the creation of the text. The mode of discourse is 'the particular functions that are assigned to language in this situation, and the rhetorical channel that is therefore allotted to it'. Christie and Unsworth (2000, p.7) agrees with Martin (1992a) that there is bi-directional relationship between language and context of situation as indicated above.

Interpersonal metafunction is thus a piece of interaction between the speaker and the listener (Halliday 1985, p. 20), and by extension, between the writer and the reader as the case in online learning interactions. Halliday observes that the speaker is using language as the means of own intrusion into the speech event: the expression of his comments, attitudes and evaluations, and also of the relationship that he sets up between himself and the listener in particular, the communication role that he adopts of informing, questioning, greeting, persuading, and the like (Halliday, 1971).

Structurally, the interpersonal metafunction is represented by mood and modality. Mood and Modality are generally used to express the interpersonal meaning. Mood expresses what role the speaker selects in the communication situation and what role he assigns to the addressee (listener or reader). Mood, as used in English, is made up the two elements (subject and finite) of a clause. This in turn determines the form of the clause which could be imperative, declarative, or interrogative. Modality involves words that mark necessity, possibility or impossibility such as should, probably, maybe, etc. (Daulay, 2011). Wang (2010, p. 225) also noted that the interpersonal function embodies all uses of language to express social and personal relations which includes the various ways the speaker enters a speech situation and performs a speech act.

Thus the paper is aimed at employing the frameworks of SFL in analyzing some commonly-found linguistic expressions in Blackboard and Moodle. Part of the objectives is to see how nominalizations used can be used to achieve meaning. It is also to explore the kinds of interactions maintained in LMS through the use of Mood; and to show that an understanding of (online learning) context is vital for purposeful student-teacher interaction.

\section{Method and data}

The method adopted is qualitative. Samples of commonly used linguistic expressions in interacting with learners via LMS are analyzed. Some of the expressions are obtained from an open source platform - Moodle - as adapted by Jubail Technical Institute solely for conducting quizzes and examinations for its students. Others are obtained from the proprietary Blackboard. The Blackboard is currently used by the three tertiary institutions owned by the Royal Commission in Jubail, Saudi Arabia. However, we have made no distinction between the data obtained from the two sources because our interest is not to create distinctions but to generally look into how language is used generally in these LMS as a means of instruction and direction for learners.

As observed above, context plays significant role in understanding the message contained in a text. At the background of our analysis is the notion of context expounded by Michael Halliday and Ruqaiya Hassan (1985, 1989). Thus, analytical focus on field of discourse, tenor of discourse and the mode of discourse presents the picture of context in which the expressions are used. Based on this understanding, analysis is done with deeper concentration on the use of nominalization (Eggins, 2012, p. 94-95) and the semantics of interaction instantiated by Mood (Eggins, 2012, p. 151161). All of these assist in engaging various expressions used in the Moodle and Blackboard, which, in turn, help in understanding how learners with limited English proficiency can work with LMS as he/she acquires the target language. The following are links and instructions extracted from Moodle and Blackboard. 
3.1 Extract A: Expressions in clauses/groups

I. You are not logged in. II. Log in. III. You have quizzes that are due. IV. One attempt(s) made on this quiz. V. This quiz will close on Tuesday at... VI. To attempt this quiz you need to know the quiz password. VII. Time limit: 50 minutes. VIII. The quiz has a time limit. IX. Are you sure that you wish to start? X. You are logged in as... XI. No Course or Organization Announcements have been posted in the last 7 days. XII. No tasks due. XIII. Create Forums to organize discussions. XIV. No items found. XV. Edit Notification Settings. XVI. Forums are made up of individual discussion threads that can be organized around a particular subject. XVII. What's new. XVIII. What's Past Due.

\subsection{Extract B: Expressions consisting of one or two lexical items}

Home, My Home, Courses, My Courses, My Profile, Courses/Organizations, Needs Attention, Administration, My profile settings, Edit profile, Change password, Messaging, Blogs, Badges, Announcements, Calendar, Tasks, My Grades, Send Email, User Directory, Address Book, Personal Information, Goals, Course Entry Page, Home Page, Discussions, Groups, Tools, Help

One of the elements instantiated through instructions and links in Moodle and Blackboard is nominalization. Nominalization is simply turning things that are not normally nouns into nouns. In other words, it is a way of turning processes (verbs) into actions and/or action-oriented expressions.

\section{Analysis: interaction and meaning potentials in the clauses}

Halliday and Matthiessen (2004, p. 106-111) considers the grammar of interaction from semantic perspective (see Eggins, 2004). They mean that as we use language to interact, we establish a relationship between us (the speaker or writer) and the person listening or reading. In the analysis of interpersonal metafunction, we look at mood and modality. As mentioned above, the major grammatical components of Mood (as interpersonal function) is MOOD and RESIDUE. The MOOD constitutes the Subject and the Finite. The RESIDUE on the other hand constitutes a PREDICATOR, one or more COMPLEMENTS, and a number of different types of ADJUNCTS (Eggins, 2012). All of these determine the form of the clause: whether it is an imperative, declarative or interrogative. Modality focuses on those words that mark necessity, possibility or impossibility such as should, probably, maybe, etcetera.

The first part of the data is made up of elements that can best be described as clauses. Structurally, they are made up Subject (the nominal component) and Predicate (the verbal component). This structure assists us to know that there is an ongoing interaction between the author (the teacher) of e.g. 'You are not logged in' and the reader (student) who is being notified. In terms of interaction, the clause is declarative. It is expressing a present state. Since it is an online interaction, it is assumed that time the information is read by the student(s) and the time of response is that time of interaction. In this case, the nominal 'You' referred to the student who is being addressed. By this function, the clause can be classified into MOOD and RESIDUE as shown in the following table A below. The Finite component take the negative 'not' which will require a positive tag 'Are you'?

Table A shows a classification into Mood and Residue

\begin{tabular}{cccc}
\hline You & are not & logged & in \\
\hline Subject & Finite & Predicator & \\
\hline & MOOD & & RESIDUE \\
\hline
\end{tabular}

Other related clauses that attempts to perform declarative function are 'You have quizzes that are due' 'One attempt(s) made on this quiz', 'No Course or Organization Announcements have been posted in the last 7 days', 'To attempt this quiz you need to know the quiz password'. However, considering the context in which these statements are made, we can see that there are participants who are interacting in the setting that can be described as formal or semiformal. The mention of a quiz in at least clauses III, V and VI, suggests a learning environment. This is because it is in the formal learning environment that quizzes take place. Thus, a learner can use his/her understanding of the context of the lexical item 'quiz' to decipher the general meaning of the other components of the sentence.

In contrast, clauses such as Log in (II) and Create Forums to organize discussions (XIII) and Edit Notification Setting $(X V)$ appear to possess an interactive function of imperative Mood. Certain actions are required to be carried out. Also, a kind of relationship is being foregrounded in the sense that the reader may probably have no alternative option than to carry out the 'command'. Language has been described to involve 'interactions where we initiate or respond to the act of giving or demanding for goods-and-services or information' (Halliday, 1994, p.64). Structurally, expressions such as in (II) appears to be made up of Residue solely. In simple present or simple past verbs, the finite element gets fused with another element known as Predicator. Eggins (2004, 2012), explains that 'in earlier forms of English, and still in the emphatic forms of contemporary English, these forms (do, did) used to be present in the main part of the clause as well as in the tag. In English grammar, do can also occur at the beginning of an imperative sentence to emphasize the importance of that imperative verb or clause. The point being made here is that the word 'do' is actually regardless of whether is explicitly mentioned or not. This is similar to what we see in the table B below: 
Table B presents another example of the classification

Do

Subject
Finite

MOOD $\log$

in

\begin{tabular}{cccc}
\hline & Finite & Predicator & \\
\hline Subject & MOOD & & RESIDUE \\
\hline
\end{tabular}

Therefore, the obscured subject may be 'You' which represents the individual learner using the online tool. What is therefore happening is an enactment of interpersonal relationships (personal and social). Personal, because the learner is personally responsible for what he/she does and he/she does it; and social because the process of interaction is taking place in a presumed social setting of learning.

In the two LMSs, there are examples of clauses that points to interrogation or question. The function is to ask short questions: 'Are you sure that you wish to start?'(IX), 'What's new.' (XVII), 'What's Past Due.'(XVIII). The (IX) is called polar interrogatives (see Eggins, 2004). It is structurally complex as it made up a main clause and a subordinate clause; and it can be analyzed based on individual clauses as shown in the table $\mathrm{C}$ below.

Table $\mathrm{C}$ shows a more complex analysis

\begin{tabular}{|c|c|c|c|c|c|}
\hline Are & you & sure that & you & wish & to start \\
\hline Finite & Subject & Predicator & Subject & Finite & Predicator \\
\hline & & RESIDUE & & & RESIDUE \\
\hline
\end{tabular}

Eggins (2004, 2012, p.168) re-echoes the involvement of WH interrogative in analyzing mood. This is identified with the presence of a WH element. When WH element is used, it is conflated or fused with another element of clause structure; and is shown as a constituent of the MOOD or RESIDUE according to the status of the element with which it is conflated. Although the clauses (XVII) and (XVIII) are written without the question mark (from the source), analysis shows that they are probably meant to serve an interaction purpose not necessarily a question. It is textually position as link through which any new information or assignment can be sourced from the LMS. In terms of structure, there represent question which the user of the LMS can probably ask himself/herself. 'What is' will fall under MOOD while 'new' and 'due' will align with RESIDUE respectively. Seeing the two clauses online such LMS requires that the learner incorporation his knowledge of context to escape confusion.

\section{Analysis: interaction and meaning potential in words and phrases}

For learners, the meaning of various nominal expressions as used in LMS can be achieved (by learners) when the context of situation of their use is considered along with other processes such as nominalization. The Extract B, which is being considered here, is made up of words and phrases. With the structural make-up of the links and instructions (in form of single lexical item and phrases), the learners are required to partake in certain communication endeavor and take certain actions. Understanding the ramifications of meanings embedded in those expressions can greatly enhance understanding. From the table below, the first column contains one-word expressions. What is being expected here is the user to take certain actions, however the action-oriented words have been condensed into noun forms. This can be described as nominalization. Sušinskienè (2010) maintains that 'nominalization allows eliminating information like participants, time or modality'. To him the "nominalization is 'materially' related to the clause; semantically it is related to the propositional content of the clause" (Sušinskienè, 2010, p. 144). This relationship with the clause supports the fact that certain action-related activity may have been condensed in those lexical components as seen below. For instance, the 'Home' may probably be telling the learner that all information regarding the learning platform can be accessed there and not the home as where people live. Our understanding of context of situation from the perspective of the field of discourse as relating the ongoing activity or experience, (which is online learning); tenor of discourse as interactants or 'players' in the language of Halliday $(1985$, p.30) (teacher and student or student and student), and the mode of discourse which is done (here) through writing (using computer) help to conceptualize the kind of message the lexical items are trying pass. See table D:

Table D presents structural description and the anticipated learner actions (in largely single lexical item)

\begin{tabular}{lcl}
\hline \multicolumn{1}{c}{ Lexical items } & Structural description & \multicolumn{1}{c}{ Action-focused on } \\
\hline Home & $\mathrm{N} / \mathrm{C} / \mathrm{S}$ & getting necessary information \\
\hline Courses & $\mathrm{N} / \mathrm{C} / \mathrm{P}$ & accessing your courses or subjects of study \\
\hline Messaging & Gerund $(\mathrm{N}) / \mathrm{S}$ & sending a message or messages \\
\hline Blogs & $\mathrm{N} / \mathrm{C} / \mathrm{P}$ & participating in the discussion in the blog \\
\hline Badges & $\mathrm{N} / \mathrm{C} / \mathrm{P}$ & accessing your learning achievements \\
\hline Announcements & $\mathrm{N} / \mathrm{C} / \mathrm{P}$ & reading and taking notes of announcements \\
\hline
\end{tabular}




\begin{tabular}{lll}
\hline Calendar & N/C/S & view the (learning) calendar \\
\hline Tasks & N/C/P & exploring the things to do \\
\hline Goals & N/C/P & exploring the various study milestones \\
\hline Courses/Organizations & N/C/P & looking through how the courses are organized \\
\hline Administration & N/C/S & knowing how the study is organized \\
\hline Discussions & N/C/P & participating in discussions \\
\hline
\end{tabular}

Structural description- $\mathbf{N}$ : Noun, $\boldsymbol{C}$ : Count, $\mathbf{S}$ : Singular, P: Plural

A study of expression such as 'Announcement, Tasks and Discussion' may require a student to read announcements made in relation to the course of study, look at activities such as assignments he/she needs to turn in, as well as to see what others are saying in relation the course. The first level of the context of situation is for identifying the environment and relation that environment to the expression. We can see more of interpersonal function in the use of the possessive "my' in the table below. The five noun phrases preceded by the possessive adjective is creating an atmosphere of familiarity which can assist the learner that remove any form of apprehension that goes with learning.

Table E presents structural description and the anticipated learner actions (in largely two-word phrases)

\begin{tabular}{|c|c|c|}
\hline Phrases & Structural description & Action-focused on \\
\hline My Home & NP & \multirow{5}{*}{$\begin{array}{l}\text { Inviting the learner to a more personal arena. } \\
\text { The possessive adjective expresses the connection of } \\
\text { home, courses and profile, profile settings and grades } \\
\text { to the learner. It carves out the LMS area to the } \\
\text { learner. }\end{array}$} \\
\hline My Courses & NP & \\
\hline My Profile & NP & \\
\hline My profile settings & NP & \\
\hline My Grades & NP & \\
\hline Change password & $\mathrm{V} / \mathrm{C}$ & requesting the learner to change password \\
\hline Send Email & $\mathrm{V} / \mathrm{C}$ & requesting the learner to draft and send email \\
\hline User Directory & NP & inviting the learner to view other users \\
\hline Personal Information & NP & $\begin{array}{l}\text { requesting the learner to view (edit or change) } \\
\text { personal information }\end{array}$ \\
\hline Course Entry Page & NP & instructing the learner to view courses \\
\hline Needs Attention & $\mathrm{V} / \mathrm{C}$ & calling the learner to what needs to be responded to \\
\hline
\end{tabular}

Structural description- NP: Noun Phrase, V: Verb, C: Complement

As seen above, the phrasal expressions require the user or learner to perform certain actions which is based on an understanding of what the structures represent. The argument being foregrounded here is that the use of LMS such as Moodle and Blackboard could be a daunting task for (adult) learners with 'humble' background in English. When learners contend with difficulties in understanding instructions, it can substantially affect their overall activities and understanding of the subject. However, by approaching instructional expression and links with consideration of the context of usage and the parties involved in the communication, learners can have a great deal of what to do and how to do what to do in any typical LMS.

\section{Conclusion}

This paper picks interest in the commonly-used expressions in LMS and analyzes the ramifications of linguistic interpretations that a learner may require to be able to use the system effectively. First, it is argued that the LMS such as Moodle and Blackboard also involve interaction. Although, the interaction is substantially done through writing, it however creates great opportunity for teachers and the learners to engage in a number of interpersonal functions. Lessons, assignments and checking information and announcements are forms of tutor-learner interaction.

It is also maintained that these interactions are foregrounded and made possible through language; and that understanding the language of instruction and direction is as important as the activity the learners aspire to do on any LMS. Thus, the aspect of language that assist in examining these online language learning at a deeper level is grounded in SFL. The context of situation as well as interpersonal meanings as provided through this functional approach to language has been utilized. It is hoped that education experts with strength in online course management system pay more attention to language and other semiotic systems that can enhance comprehension and use by learners. Learners with limited English language proficiency can, thus, advance their understanding of LMS by adapting some of the frameworks provided by the functional approach to language. 


\section{References}

Al-Jarf, R. S. (2005). Using Three Online Course Management Systems in EFL Instruction. Asia CALL Conference, 211.

Berg, R. D., \& Lu, Y. (2014). Student Attitudes towards Using Moodle as a Course Management System. International Conference on Recreation and Leisure Industry \&amp; Language Application, 327-336.

Daulay, F. Y. (2011). Systemic Functional Linguistics and Appraisal Theory. In Appraisal in the Inaugural Addresses of the Presidents of America from Bush to Obama (pp. 9-29). Medan: University of Sumatera Utara.

Eggins, S. (2012). An introduction to systemic functional linguistics. New York: Continuum.

Halliday, M. A. (1973). Explorations in the functions of language. London: Edward Arnold.

Halliday, M. A., \& Hasan, R. (1985). Language, context, and text: Aspect of language in a social-semiotic perspective. Oxford: Oxford University Press.

Halliday, M. A. (1991). The notion of 'context in language education. In T. Le \& M. McCausland (Eds.), Language education: Interaction \&amp; development (pp. 1-26). Launceston: University of Tasmania at Launceston.

Murray, D. E., \& McPherson, P. (2004). Using the web to support language learning. Sydney, N.S.W.: National Centre for English Language Teaching and Research.

Song, L. (2010). The Role of Context in Discourse Analysis. Journal of Language Teaching and Research JLTR, 1(6).

Sušinskienè, S. (2010). Nominalization as a Cohesive Device in British Newspaper Editorials. FILOLOGIJA, 15, $142-$ 150 .

Tomlin, R. S. (1990). Functionalism in Second Language Acquisition. Studies in Second Language Acquisition, 12(02), $155-177$.

Unsworth, L., \& Christie, F. (2000). Researching language in schools and communities: Functional linguistic perspectives. London: Cassell.

Wang, J. (2010). A Critical Discourse Analysis of Barack Obama's Speeches. Journal of Language Teaching and Research JLTR, 1(3).

Xiao, W., Li, W., \& Du, J. (2010). The Review of the Emotional Contagion Theory Based on the Interpersonal Perspective. 2010 International Conference on Management and Service Science. 